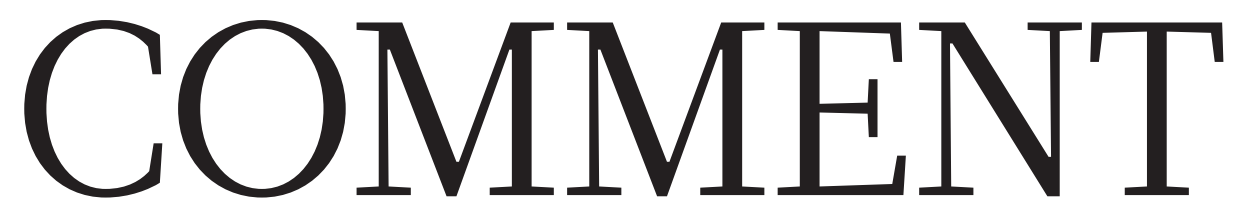

REGULATION Data suggest the FDA is overcautious on consumer genomics p.286
DEVELOPMENT Why policymakers must admit that water is finite $\mathbf{p . 2 8 8}$
ASTRONOMY Planetarium show puts dark Universe at the centre of the action $\mathbf{p . 2 9 0}$
FUNDING Grant applications should feature multimedia presentations $\mathbf{p . 2 9 1}$

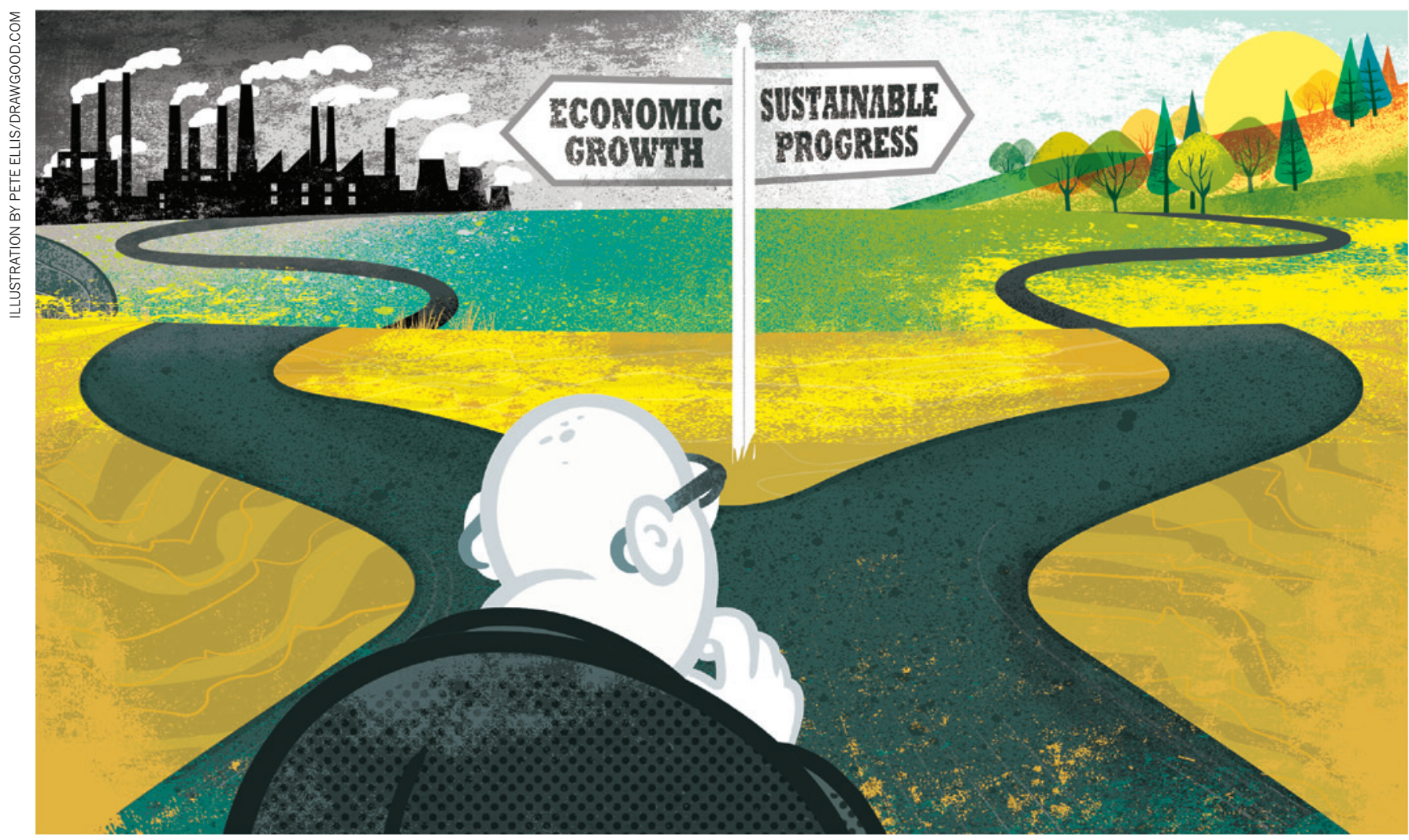

\title{
Time to leave GDP behind
}

Gross domestic product is a misleading measure of national success. Countries should act now to embrace new metrics, urge Robert Costanza and colleagues.

$\mathrm{R}$ obert F. Kennedy once said that a country's gross domestic product (GDP) measures "everything except that which makes life worthwhile". The metric was developed in the 1930s and 1940s amid the upheaval of the Great Depression and global war. Even before the United Nations began requiring countries to collect data to report national GDP, Simon Kuznets, the metric's chief architect, had warned against equating its growth with well-being.

GDP measures mainly market transactions. It ignores social costs, environmental impacts and income inequality. If a business

used GDP-style accounting, it would aim to maximize gross revenue - even at the expense of profitability, efficiency, sustainability or flexibility. That is hardly smart or sustainable (think Enron). Yet since the end of the Second World War, promoting GDP growth has remained the primary national policy goal in almost every country ${ }^{1}$.

Meanwhile, researchers have become

\section{DNATURE.COM}

For more on

sustainable

development goals:

go.nature.com/ttayln much better at measuring what actually does make life worthwhile. The environmental and social effects of GDP growth can be estimated, as can the effects of income inequality ${ }^{2}$. The psychology of human wellbeing can now be surveyed comprehensively and quantitatively ${ }^{3,4}$. A plethora of experiments has produced alternative measures of progress (see Supplementary Information; go.nature.com/bnquxn).

The chance to dethrone GDP is now in sight. By 2015, the UN is scheduled to announce the Sustainable Development Goals, a set of international objectives to improve global well-being. Developing integrated measures of progress attached to these goals offers the global community the opportunity to define what $>$ 
sustainable well-being means, how to measure it and how to achieve it. Missing this opportunity would condone growing inequality and the continued destruction of the natural capital on which all life on the planet depends.

\section{DETHRONING GDP}

When GDP was instituted seven decades ago, it was a relevant signpost of progress: increased economic activity was credited with providing employment, income and amenities to reduce social conflict and prevent another world war.

But the world today is very different from the one faced by the global leaders who met to plan the post-war economy in 1944 in Bretton Woods, New Hampshire. The emphasis on GDP in developed countries now fuels social and environmental instability. It also blinds developing countries to possibilities for more-sustainable models of development.

Soaring economic activity has depleted natural resources. Much of the generated wealth has been unequally distributed, leading to a host of social problems ${ }^{5}$. The philosopher John Stuart Mill noted more than 200 years ago that, once decent living standards were assured, human efforts should be directed to the pursuit of social and moral progress and the increase of leisure, not the competitive struggle for material wealth. Or as the economist John Kenneth Galbraith once observed: "To furnish a barren room is one thing. To continue to crowd in furniture until the foundation buckles is quite another."

The limits of GDP are now clear. Increased crime rates do not raise living standards, but they can lift GDP by raising expenditures on security systems. Despite the destruction wrought by the Deepwater Horizon oil spill in 2010 and Hurricane Sandy in 2012, both events boosted US GDP because they stimulated rebuilding.

\section{WEIGHING THE ALTERNATIVES}

Alternative measures of progress can be divided into three broad groups (see Supplementary Information). Those in the first group adjust economic measures to reflect social and environmental factors. The second group consists of subjective measures of well-being drawn from surveys. The third group relies on weighted composite indicators of well-being including housing, life expectancy, leisure time and democratic engagement.

Adjusted economic measures. These are expressed in monetary units, making them more readily comparable to GDP. Such indices consider annual income, net savings and wealth. Environmental costs and benefits (such as destroying wetlands or replenishing water resources) can also

be factored in. One example is the genuine progress indicator (GPI). This metric is calculated by starting with personal consumption expenditures, a measure of all spending by individuals and a major component of GDP, and making more than 20 additions and subtractions to account for factors such as the value of volunteer work and the costs of divorce, crime and pollution ${ }^{6}$.

Crucially, unlike other measures in the first group, GPI considers income distribution. A dollar's worth of increased income to a poor person boosts welfare more than a dollar's worth of increased income does for a rich person. And a big gap between the

"GDP is dangerously inadequate as a measure of quality of life." richest and the poorest in a country - as in the United States and, increasingly, in China and India correlates with social problems, including higher rates of drug abuse, incarceration and mistrust, and poorer physical and mental health ${ }^{5}$.

These adjustments matter. A 2013 study ${ }^{2}$ comparing the GDP per capita and the GPI per capita of 17 countries comprising just over half the global population found startling divergences between the two metrics. The measures were highly correlated from 1950 until about 1978, when they moved apart as environmental and social costs began to outweigh the benefits of increased GDP (see 'Genuine progress flattens'). Tellingly, life satisfaction is highly correlated with GPI per capita, but not with GDP per capita.

Some governments are taking this seriously. Two US states, Vermont and Maryland, have in the past three years adopted GPI as a measure of progress and have implemented policies specifically aimed at improving it.

Subjective measures of well-being. The most comprehensive of these is the World Values Survey (WVS), which covers about 70 countries and includes questions about how satisfied people are with their lives. Starting in 1981, the WVS is conducted in 'waves', the sixth of which is currently in progress. Another example is the gross national happiness index used in Bhutan. This measure uses elaborate surveys that ask how content people feel in nine domains: psychological well-being, standard of living, governance, health, education, community vitality, cultural diversity, time use and ecological diversity.

Subjective well-being has been highly studied, and has even been recommended as the most appropriate measure of societal progress ${ }^{7}$. But subjective indicators are tricky to compare across societies and cultures. For example, self-reported health tracks with clinically reported rates of morbidity and mortality within countries but not across them ${ }^{8}$. And people are not always aware of the things that contribute to their well-being. Few of us give credit to ecosystem services for water supply and storm protection, for example.

Weighted composite measures of several indicators. A comprehensive picture of sustainable societal well-being should integrate subjective and objective indicators ${ }^{9}$ (see Supplementary Information, Figure S1), as these measures begin to do. One example is the Happy Planet Index, introduced by the New Economics Foundation in 2006. This multiplies life satisfaction by life expectancy and divides the product by a measure of ecological impact.

Other indices in the third group combine a range of variables, such as income, housing, jobs, health, civic engagement, safety and life satisfaction. The Better Life Index, developed by the Organisation for Economic Co-operation and Development, maintains a website that allows users to choose how to weight variables, revealing how the emphasis on different variables can influence countries' rankings.

Many other experiments are under way (see www.wikiprogress.org). None of these measures is perfect, but collectively they offer the building blocks for something much better than GDP.

\section{WHY ARE WE STUCK?}

There is broad agreement that global society should strive for a high quality of life that is equitably shared and sustainable. Several groups and reports have concluded that GDP is dangerously inadequate as a measure of quality of life - including those published by the French government's 2008 Commission on the Measurement of Economic Performance and Social Progress ${ }^{10}$, the Frederick S. Pardee Center for the Study of the Longer-Range Future ${ }^{11}$ and the European Commission's ongoing Beyond GDP initiative. That conclusion was also echoed in 'The Future We Want', the declaration

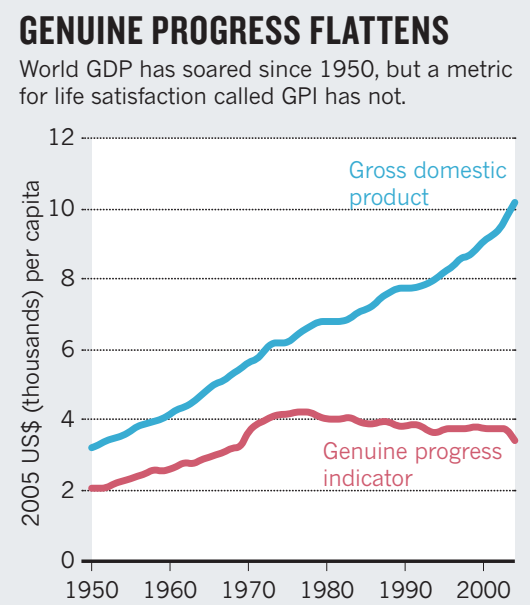



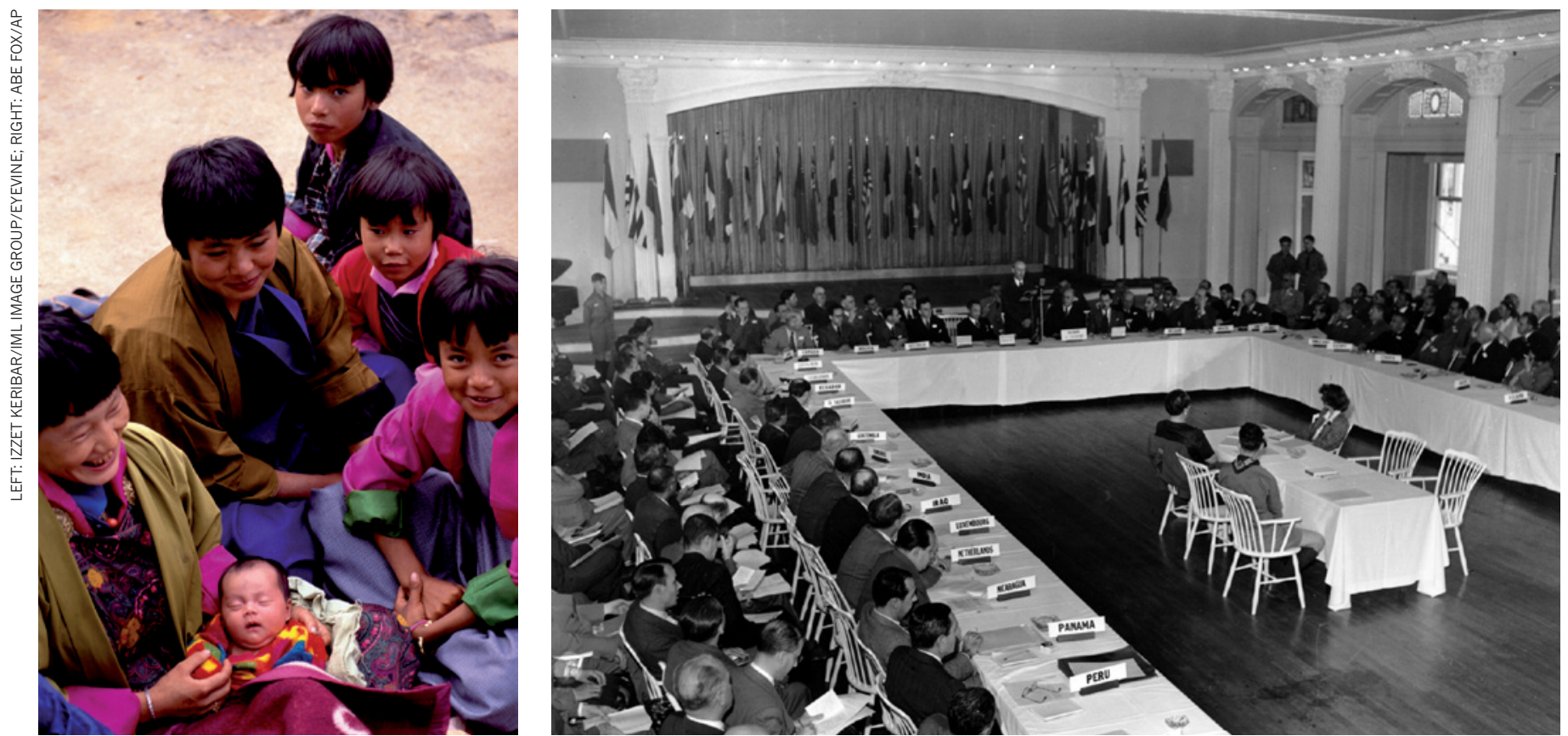

Bhutan has measured citizens' well-being using gross national happiness since 2008 (left); GDP has been in use since the 1944 Bretton Woods meeting (right).

of the 2012 Rio+20 UN Conference on Sustainable Development agreed to by all UN member states.

Nonetheless, GDP remains entrenched ${ }^{1}$. Vested interests are partly responsible. Former US President Bill Clinton's small move towards a 'green GDP', which factored in some of the environmental consequences of growth, was killed by the coal industry. However, much of the problem is that no alternative measure stands out as a clear successor.

Creating that successor will require a sustained, transdisciplinary effort to integrate metrics and build consensus. One potential vehicle for doing this is the setting up of the UN Sustainable Development Goals (SDGs), a process that is now under way to replace the Millennium Development Goals (MDGs). Established in 2000, the MDGs comprise eight basic targets that include eradicating extreme poverty and establishing universal primary education, gender equality and environmental sustainability. Currently both the MDGs and the suggested SDGs are only lists of goals with isolated indicators. But the SDG process can and should be expanded to include comprehensive and integrated measures of sustainable well-being ${ }^{12}$.

If undertaken with sufficiently broad participation, the hunt for the successor to GDP might be completed by 2015. There are significant barriers to doing this, including bureaucratic inertia and the tendency of governments, academia and other groups to work in isolation. These barriers can be overcome with dedicated leadership. Crucially, people can now communicate across the globe with an ease unthinkable in the days of Bretton Woods.
Any 'top-down' process must be supplemented with a 'bottom-up' engagement of civil society that includes city and regional governments, non-governmental organizations, business and other parties. We recently formed the Alliance for Sustainability and Prosperity (www.asap4all.com) to do just that. This web-based 'network of networks' can communicate research about sustainable quality of life and the elements that contribute to it (see Supplementary Information), and so help to build consensus among the thousands of groups now concerned with these issues.

The successor to GDP should be a new set of metrics that integrates current knowledge of how ecology, economics, psychology and sociology collectively contribute to establishing and measuring sustainable wellbeing. The new metrics must garner broad support from stakeholders in the coming conclaves.

It is often said that what you measure is what you get. Building the future we desire requires that we measure what we want, remembering that it is better to be approximately right than precisely wrong.

\section{Robert Costanza and Ida Kubiszewski} are at the Crawford School of Public Policy, Australian National University, Canberra. Enrico Giovannini is in the Department of Economics and Finance, University of Rome Tor Vergata, and minister of labour and social policies in the Italian government. Hunter Lovins is at Natural Capital Solutions, Longmont, Colorado. Jacqueline McGlade is at University College London, and the United Nations Environment Program, Nairobi, Kenya. Kate E. Pickett is in the Department of Health Sciences, University of York, UK. Kristín Vala Ragnarsdóttir is at the Institutes of Earth Sciences and Sustainable Development Studies, University of Iceland, Reykjavík. Debra Roberts is in the Environmental Planning and Climate Protection Department, eThekwini Municipality, Durban, South Africa. Roberto De Vogli is at the University of California, Davis. Richard Wilkinson is in the Division of Epidemiology and Public Health, University of Nottingham, UK.

e-mail: robert.costanza@anu.edu.au

1. Van den Bergh, J. C. J. M. J. Econ. Psychol. 30 , 117-135 (2009).

2. Kubiszewski, l. et al. Ecol. Econ. 93, 57-68 (2013).

3. Diener, E. \& Suh, E. M. in Well-Being: The Foundations of Hedonic Psychology (eds Kahneman, D., Diener, E. \& Schwarz, N.) 434-450 (Russell Sage Foundation, 2003).

4. Seligman, M. E. P. Flourish: A Visionary New Understanding of Happiness and Well-being (Atria, 2012).

5. Wilkinson, R. G. \& Pickett, K. The Spirit Level: Why Greater Equality Makes Societies Stronger (Bloomsbury, 2009).

6. Talberth, J., Cobb, C. \& Slattery, N. The Genuine Progress Indicator 2006: A Tool for Sustainable Development (Redefining Progress, 2007).

7. Layard, R. Happiness: Lessons from a New Science (Penguin, 2005).

8. Barford, A., Dorling, D. \& Pickett, K. Social Sci. Med. 70, 496-497 (2010).

9. Costanza, R. et al. Ecol. Econ. 61, 267-276 (2007).

10.Stiglitz, J. E., Sen, A. \& Fitoussi, J.-P. Report by the Commission on the Measurement of Economic Performance and Social Progress Vol. 12 (Commission on the Measurement of Economic Performance and Social Progress, 2009).

11. Costanza, R., Hart, M., Posner, S. \& Talberth, J. Beyond GDP: The Need for New Measures of Progress (Boston University, 2009).

12.Griggs, D. et al. Nature 495, 305-307 (2013). 